\title{
VOICES, OPPORTUNITIES \& CHOICES EMPLOYMENT CLUB: TRANSFORMING SHELTERED WORKSHOPS USING AN AFFIRMATIVE BUSINESS APPROACH
}

\author{
TERRY KRUPA, KAREN MCCOURTY, \\ DOUG BONNER, BARBIE VON BRIESEN, \\ and ROBERT SCOTT \\ On behalf of the VOCEC Board of Directors
}

\begin{abstract}
Voices, Opportunities \& Choices Employment Club (VOCEC) is a nonprofit "umbrella" corporation that facilitates the development of affirmative businesses to create jobs for consumers of mental health services. To date, 5 independent businesses have been developed by transforming the resources of sheltered workshops within Kingston Psychiatric Hospital and 2 businesses have been established in collaboration with a local public library. This paper provides a description of VOCEC, including an overview of the affirmative business approach, the structure of the organization, and the process of business development. Personal reflections provide insights into the experiences of consumers, staff, and Board members associated with the corporation.
\end{abstract}

\section{INTRODUCTION}

The Ontario Ministry of Health's 1990 operational review recommended a drastic reduction in sheltered workshops in Provincial Psychiatric Hospitals. Consistent with the emergent paradigm in the vocational rehabilitation field, the review stressed real employment opportunities in community-based settings as the preferred outcome. It called for the development of community-oriented vocational resources that capitalized on the strengths of consumers of mental health services and worked directly within the community to create employment opportunities (Philips Group, 1990).

In response to the operational review, a Vocational Rehabilitation Task Force was established at Kingston Psychiatric Hospital to make recommendations for the design and implementation of a comprehensive system of community-oriented vocational services. Following research into current employment approaches, the task force suggested the development of affirmative businesses as one of the elements of a new system of vocational resources. It was believed that this community economic development approach had the potential to significantly increase work opportunities by focusing efforts primarily towards broader economic conditions that perpetuate unemployment (Bennett, 1992). Community economic development provided an alternate framework to the traditional rehabilitation approaches that interpreted unemployment and social marginalization primarily as a result of individual characteristics related to mental disorder (Krupa, 1998; 
Trainor \& Tremblay, 1992; Warner \& Polack, 1993). The approach also addressed concerns related to the barriers posed by securing work opportunities in a region with a relatively high unemployment rate and it capitalized on the physical resources that became available with the closing of the workshops. In addition, examples of community economic development within the mental health arena indicated that the approach had the potential to strengthen the consumer community and facilitate the level of consumer involvement and ownership (Allen \& Granger, 1996; Friesen \& Viti, 1994: Hartl, 1992; Trainor \& Tremblay, 1992).

Initial efforts to develop a knowledge base about consumer-operated businesses included meetings with the Ministry of Health's Mental Health Facilities Branch and Ontario's Consumer Survivor Development Initiative, as well as visits with existing consumer-run businesses. While this laid the foundation for interest in and commitment to the consumer-directed business option, there were no existing models for the transformation of hospital-based sheltered workshops.

Early in 1993 both formal and informal meetings were held with consumers of Kingston Psychiatric Hospital vocational services and vocational staff to share information and to develop support and commitment for affirmative businesses. A volunteer Board of Directors was formed to develop the organizational structure and to encourage consumers and staff to begin a process of business planning around existing physical resources. Central to this planning and development process was the explicit support of the Ministry of Health to transform the existing resources of vocational services into affirmative businesses. The administration of Kingston Psychiatric Hospital provided support in the form of physical resources (staff reallocation and the overhead costs, space, equipment, and customer base associated with the former workshops) and the unwavering belief in the values and goals underlying the planning process. In addition, the redirection of sheltered workshop revenues from the central provincial treasury to the affirmative businesses enabled the process of business development and planning.

In November 1993, the Voices, Opportunities \& Choices Employment Club (VOCEC) was incorporated as a not-for-profit corporation with a defined mission statement, objectives, and by-laws. This "umbrella" corporation was designed to facilitate the development of affirmative businesses in order to provide meaningful employment opportunities, with fair remuneration, for persons with psychiatric disabilities.

This paper provides a description of VOCEC-including an overview of the affirmative business approach, the structure of the organization, and the process of business development. A significant portion of the paper is devoted to discussing some of the challenges that VOCEC is facing. The paper is a collective effort between members of the VOCEC Board of Directors and includes personal reflections contributed by consumers, staff, and Board members.

I have been an Associate of VOCEC since March of 1998. In that time, I have used my marketing skills to work as a cashier. Because of the independence required, I have become more self-motivated. What has been great for me is that it has provided a bridge towards a goal of full-time employment. I have appreciated the constructive criticism and satisfaction that $I$ obtain from my work. The most useful thing that I have leamed is to focus on my ability to do a job well. Work of this nature puts a proper perspective on life and creates a 
sense of optimism while building on important skills. The feeling of competence that comes from doing a job well is as valuable as the money from the pay cheque.

(G.S., Associate of VOCEC)

\section{THE AFFIRMATIVE BUSINESS APPROACH}

VOCEC operates on the assumption that the high unemployment rates of mental health consumers are, to a large extent, socially determined by labour market forces which favour individualism, competition, and profit. Thus, it adopts an affirmative business approach. The affirmative business approach develops partnerships between consumers of mental health services, service providers, and business people. By facilitating the production of goods and services which can be sold in the broader community, it creates job opportunities for people with psychiatric disabilities.

The affirmative business approach attempts to neutralize the factors which disadvantage people with psychiatric disabilities in several ways:

The success of a business is evaluated by its economic sustainability and its ability to strengthen the consumer community. Consequently, business decisions are directed to increasing profits but only in the context of: (a) increasing the employment opportunities available to consumers, (b) facilitating consumer involvement and ownership, (c) building on the strengths of the consumer collective, (d) improving the real life conditions of consumers, and (e) meeting or exceeding standards for fair employment.

The benefits of community integration that are associated with work are realized at the level of the businesses. Through their associations with local business networks and community organizations (for example, membership with the Greater Kingston Chamber of Commerce) the businesses are associated with efforts to promote the community economic development of the Greater Kingston area. In the context of the day-to-day operation of the businesses, consumers are in contact with other members of the broader Kingston community. This employment provides them with an accepted social identity and with the well-being and autonomy associated with an increase in level of income.

The policies and procedures of the businesses are developed to facilitate the production of the goods and services and to accommodate those employment characteristics that are associated with severe psychiatric disorders. Since operational issues are dealt with largely at the level of the individual business, the consumers are directly involved in decisions related to reasonable accommodations and to the responsibilities of individual employees to the business. For example, the most prevalent accommodation is flexibility in scheduling to allow for time off from work due to illness-related issues.

The mission and the day-to-day operation of VOCEC are directed to business and work issues rather than to the treatment and rehabilitation focus that was prevalent in the sheltered workshops.

As well as providing jobs, the VOCEC Board provides a leaming and training opportunity for the Board members who are also consumers, I personally feel 
very fortunate to have gained experience in running and participating on the Board. Other spin-offs have been leaming to speak in public, conflict resolution within the businesses, what problems there are in business, interviewing skills, and of course getting some personal gratification that I am doing something useful in my life.

(Doug Bonner. President, VOCEC)

\section{THE STRUCTURE OF VOCEC}

The consumers who work in the individual affirmative businesses are considered "Associates" and are all members of vOCEC with full voting privileges. Employment with the businesses is open to any individual who has been a consumer of mental health services.

VOCEC is currently governed by a volunteer, elected, Board of Directors. The Board consists of up to eight members, and represents a mix of consumers, service providers, and business people from the local community. Fifty percent of the Board membership is reserved for consumers of mental health services. Board members cannot be employed within any of the affirmative businesses to avoid the conflicts of interest that are likely to occur at this level of decision-making.

The roles and the responsibilities of the Board of Directors include: overseeing the development and implementation of a number of individual affirmative businesses; assisting with the ongoing development of business plans; providing financial advice and assistance to individual businesses; and, facilitating the development of new business ideas and opportunities. A percentage of the profits from each of the individual affirmative businesses are flowed to vOCEC in the form of corporation fees, to be used as seed money for the development of new community-based businesses.

In addition to the corporation's bylaws, VOCEC has established basic operational policies that apply to all affirmative businesses. These policies outline the nature of the relationship between VOCEC and the affirmative businesses, express the values and beliefs of the corporation, and uphold federal and provincial employment regulations.

Each of the affirmative businesses operated under the auspices of VOCEC has its own identity, including its own name, mailing address, and telephone. Typically, a new business begins as a pilot venture to take stock of resources, develop il market base for the product, complete business plans, and to attend to the details of the business operation. At present, Kingston Psychiatric Hospital staff are allocated to each of the businesses for the purpose of facilitating the active involvement of all of the Associates. Decisions regarding day-to-day operation are made at the level of the individual business and all Associates are encouraged to participate in all of the work of the business.

In 1994 I was volunieered to participale with VOCEC by a friend who works at $K P H$. At the outset I was reluctant to become involved because I thought that VOCEC would be just another make work program from the Govemment. Boy, was I WRONG!

Once I became involved with VOCEC in the formation of the corporation and the businesses, I realized that the Associates were receiving a tremendous 
value from running their own companies in that they were benefiting from the therapy of work! The changes I see every month in the people are overwhelming in that they no longer shufle around quietly with their heads doun. They are excited about their work and talk incessantly about the business. They are moving towards a rewarding lifestyle that they all once enjoyed. I am impressed at the professionalism of the Associates and their approach to their businesses. They truly do nun the businesses.

My rote on the Board of Directors has evolved from pushing the Board to think about the possibilities in bussiness to trying to seize the opportunities that are presented by the Board in an organized manner.

(Bob Scolt, Director, VOCEC Baard of Directors)

\section{BUSINESS DEVELOPMENT}

To date, VOCEC has approached business development from three angles. Initially the focus was on the transformation of the resources of the sheltered workshops into affirmative businesses. This involved reconstructing the service provider-client relationship to one of partnership, shared leadership, and shared decision making.

In the traditional sheltered-workshop model, service providers functioned in the role of workshop supervisors who oversee the day-to-day operation of the workshop and work with individual clients to increase work capacity and performance. Although the workshop staff were in a position of power over individual clients, neither staff nor consumers had ultimate control over the direction or development of the workshop. Thus, the relationship between the consumer and the provider in the affirmative business represented a shift in power relations and an opportunity for mutual growth and learning about business and community development.

As a Kingston Psychiatric Hospital employee for the past eleven years I have been a part of a shift from sheltered workshops to consumer-run businesses. For the clients involved, this meant no longer taking instructions from a workshop supervisor, rather, they are now making their own business decisions and working cooperatively with fellow business associates. Many have leamed to do payroll, banking and scheduling. I have enjoyed this shift in focus and am pleased to see the business Associates taking pride in their businesses and themselves. To assist the Associates with their business ventures I am learning new business skills as well, from Quickbooks Accounting to the legalities of business registrations. It has been a leaming process for everyone and one that we are all enjoying.

\section{(Lisa Quanz, Vocational Rehabilitation Services)}

Intense and emotional personal reactions of both service providers and consumers are inevitable in the shift to a partnership paradigm. These were perhaps particularly acute in this situation where the forces of change were external, high profile, and largely condemning of the existing workshop structure. These personal reactions included skepticism, passive acquiescence, confusion, insecurity, conflict, and interpersonal stress (Radloff-Gabriel, 1997).

The early work of the Vocational Rehabilitation Task Force began the process of involvement of all stakeholders, and secured the base of interest and commit- 
ment necessary to facilitate the process. While the sheltered workshops were organized primarily as a work-activity program with an open system of referral, the Task Force defined a mission statement that focused on assisting individuals with psychiatric disabilities to choose and achieve their personal vocational goals. This essentially changed the entry criteria by clarifying that involvement in vocational services was directed at the individual's personal interests in work. Referrals based on the recommendations of clinical staff were no longer accepted without the collaboration of the individual consumer, and there was a concomitant rise in self-initiated referrals. This change was significant in that it secured the base of consumers necessary to ensure sufficient commitment and effort for business development.

The initial momentum to establish affirmative businesses was faced with two challenges: the need to counterbalance the beliefs, knowledge base, and procedures that were associated with the sheltered workshops and were well entrenched with staff, consumers, administration, and even the broader Kingston community; and, the lack of the business expertise, among both staff and consumers, that was needed to transform the operations. To address these challenges, VOCEC implemented the following strategies, designed specifically to facilitate the change to an affirmative business approach: (a) holding information sessions with consumers and providers to learn about consumer businesses, business planning, marketing, and participatory management, (b) creating formal policies for shared business meetings and decision-making, (c) engaging in consultation with local business resources (eg., the Queen's University Small Business Consultants), (d) renaming the position of staff to "Affirmative Business Support Person," (e) undertaking education about the principles of psychosocial rehabilitation. (f) providing the infusion of start-up funds to the individual businesses, (g) obtaining rent-free space in government owned or leased buildings in lieu of business loans or government grants, (h) developing communication structures that supported direct communication between consumers and the customer base, suppliers, and the Board of VOCEC, and (i) holding an annual general meeting to provide the opportunity for the face-to-face interaction between the Associates from all of the businesses and the Board of VOCEC and for a shared review of the health of the organization (Radloff-Gabriel, 1997; VOCEC, 1994).

The Hands on Car Wash is an independent business that was formerly run by the $K P H$, and is now rum by the workers... I have found in my experience that there is less stress involved in the car wash than in a regular job, since no one has to uorry about stigma. Also, if a person is having problems... he can take time off work without losing his job. Eamings vary from person to person, depending on what days they have worked. Payment is based on profut share, with the day's receipts being divided up for the workers for that day. The cashier and the crew leader each receive an extra hour for their added responsibilities, and if they are working the moming shiff, must come in 15 minutes early to set up. Anyone can sign up for these positions, as well as signing up for which shifs they are going to work each week. I find that the car wash gets me out of the house, adds to my social life (since l consider my coworkers to be my friends), and brings in some badty needed extra money ... I consider the Hands On Car Was to be a success slory. We provide a useful service and have many loyal customers. We are a profitable business. 
based on the principle of competition .... I see no reason why we cannot continue for many years to come.

(Excerpts from a report, presented by Tony van der Kooi, VOCEC Associate, to the 1998 Annual General Meeting)

The affirmative businesses that arose from the sheltered workshops are Associate-owned and operated as profit-sharing ventures. These businesses have received exemption from the federal legislation regulating the employer/employee relationship.

The second approach to business development has focused on capitalizing local business opportunities that have been consistent with consumer interests. In 1995, the Kingston Public Library called for tenders to develop cafés on its premises. VOCEC's proposal was based on a "partnership model" that highlighted the benefits of the venture for both VOCEC and the library and their shared responsibility in ensuring the success of the business venture. This was the first business to be established using the funds acquired from corporation fees. The employment opportunities within this business have expanded to include a bookkeeping/ accounting position in addition to the direct service positions within the cafés.

The library-based business is registered directly with VOCEC. The Associates working in this business are considered employees of VOCEC and are paid an hourly rate of minimum wage. Unlike the other businesses, the cafés reflect less of a "team effort." At the present time, Associates work their own shift independently and interact with other café workers through a daily $\log$ book that allows for sharing of ideas and issues. This arrangement has provided a particular challenge to creating flexibility in scheduling, since there are no other Associates present on the job to compensate for an absent worker. In addition, the time and task demands of establishing a café kiosk have lead to an over-reliance on the services of vocational staff. For example, staff currently pick up perishable foods from suppliers and deliver them to the cafés because VOCEC has not acquired a vehicle for business use. The goal for the cafés is to continue to develop the Associates' ownership of this business through business planning meetings and shared problem solving.

A third method for business development has been to encourage mental health consumers, either individually or collectively, to advance new ideas for businesses with assistance from VOCEC in refining business ideas and creating business plans. Individuals have received assistance with setting up service-oriented businesses catering to other mental health consumers (eg., a "one-person" laundry service and a barber). A group of consumers are currently meeting to determine the feasibility of operating a retail outlet for crafts, art, and wood products.

Having been empowered by being a VOCEC Board member and doing volunteer work, and paid work, I have come to recognize the needs of many of the other friends and Associates. Serving others by using my brain to figure out how to do this has been beneficial. Being there for each other is what I've been leaming. The value of work, and the dignity it brings is a psychosocial rehabilitation principle and I think VOCEC fulfills that for us who are Associates of our businesses. Thus, and so, one bag lady becomes a Board lady and then leamis to share her abilities and love for people.

(Barbie Von Briesen, VOCEC Board of Directors) 


\title{
INDICATORS OF SUCCESS
}

At their prime, the sheltered workshops at Kingston Psychiatric Hospital provided work opportunities for well over 100 people at various sites. In the early $1990 \mathrm{~s}$, at the time of the operational review of the provincial hospital vocational services, the workshops experienced significant downsizing. By 1993, during the initial stages of the conversion to a business model, one sheltered workshop remained serving 47 people. While 50 to $60 \%$ of these workshop employees initially became VOCEC Associates, only 10 people from this group continue to work in the businesses. Concerns about the mass displacement of workers in the sheltered workshop as a result of the transformation appear to have been largely unfounded. The workshop population represented an aging group of individuals who had reached the stage of retirement or received individualized assistance to secure alternative options for productivity. In comparison, the Associates of VOCEC are younger people (with an approximate average age of thirty-five) who, it is believed, would not consider the sheltered workshop an agreeable vocational alternative.

\begin{abstract}
I love working at the Contracs Factory. It gives me the opportunity to have a purpose and dignity that $I$ am contributing to my financial independence and have regained my confidence in my work ethic Because of the way it is structured it allows me to take time off as needed or leave a shift early without being penalized. The camaraderie and peer support is great and l very much look fomard to meeting my co-workers and chatting over work or over a coffee in the Treasure Café. We take our work seriously and are concemed about getting out the recycled yam with which we make our profits. We show concem for our coworkers and offer support whether it be to make a decision about work or advice about medications, psychiatrists or family problems. We are starting to take an active role in the management and business process. Several of us have completed a payroll, there are three of us on the newty organized hiring committee which is developing policies regarding hiring, $a b$ senteeism, and work behaviours. One area we would like to go into is the actual business side and determine cost-effectiveness and go over the actual accounting and money management side of the business.
\end{abstract}

\section{(Moira Fuller, VOCEC Associate)}

Approximately 20 in-patients who participated in the workshops as part of a "ward program" were particularly affected by the changes to the program. When the sheltered workshops ceased to exist, the responsibility for rehabilitation planning for these people was transferred to the primary treatment teams. An exception occurred with the in-patient forensic services: in response to the severe constraints imposed by legal warrants, a small group of eligible in-patients, using the industrial sewing machines from the sheltered workshops, have organized their own affirmative sewing business within the VOCEC corporation.

There are currently seven businesses operating under the auspices of VOCEC. The businesses offer a range of employment opportunities and include a car wash. an industrial contract factory, sewing, a greenhouse, and three cafés. Over 70 consumers are registered as Associates with VOCEC and are gainfully employed in one of the businesses. The corporation has received several awards of recognition, including the Ontario Community Action Award and the KPH Community Advisory Board's Certificate of Excellence Award. 
With respect to income, the employees of the library cafés are paid minimum wage, but the nature of the work limits the number of hours they can work in any given week. All of the businesses offer a substantially higher income to consumers than the sheltered workshops. There is, however, considerable variation in income levels between the businesses that follow a profit-share model. An important measure of employment success is the extent to which consumers are able to meet and exceed the income limits of their disability pensions. While VOCEC is currently in the process of acquiring this information, observations and personal reports indicate a trend towards Associates approaching pension limits.

In the past three years the annual revenues of the businesses have quadrupled to approximately one quarter million dollars. This growth reflects the realization of the economic potential of these businesses and their contributions to the cconomic development of the Kingston area.

Radloff-Gabriel's (1997) qualitative study of the process of transforming a sheltered workshop to a consumer-directed business identified benefits for consumers and major changes in the nature of the consumer-provider relationship. In addition to the increased income, consumers experienced the benefits of involvement in realistic and meaningful work, consumer self-direction, and increased flexibility and accommodation on the job. At the organizational level, Radloff-Gabriel found that the business model gradually changed the work environment in a manner that reconstructed the consumer-provider relationship to a partnership that promoted equality and facilitated consumer sovereignty and self-determination. The study has been instrumental in developing a working model for transforming sheltered workshops to more consumer-directed businesses.

The biggest difference I have experienced benveen a sheltered workshop and
an Affirmative Business is a feeling-it's hard to describe. I believe it comes
from the fact that members choose to be there, they have control in the en-
viromment, and they are making real money for real work-the feeling is
power!

(Sheryl Ferguson, Vocational Rehabilitation Senices)

\section{ONGOING CHALLENGES}

In the six years since its inception, VOCEC has grown at a rapid rate and has diversified to an extent that was not originally anticipated. In spite of its considerable success, the corporation faces many ongoing challenges.

As the corporation has expanded there has been an ongoing need to revisit the corporation's mission, beliefs, practices, and procedures. Changes that appear to affect one aspect of the corporation inevitably have some impact throughout the entire organization. For example, while the creation of several different businesses Was viewed as an indicator of the corporation's ability to meet the diverse employment needs and desires of consumers, it did lead to an increase in the movement of Associates between businesses and threatened the workforce stability of individual businesses. The Board was faced with the unexpected task of developing new policies that encouraged individual choice and autonomy and yet preserved the integrity of the individual businesses. 
Each new business, whether it begins as a transformation from a sheltered workshop or as a new venture, demands considerable learning on the part of both consumers and staff. This includes learning about businesses in general and about the demands of producing the specific goods or services. For example at the greenhouse it has taken several years to learn about those crops that are particularly volatile and subsequently risky business ventures, and about those that are both hearty and in public demand.

A particularly formidable task has been achieving economic viability with sheltered workshop resources that were not originally intended for business purposes. The physical layout of the former workshops is neither large enough nor modern enough to produce goods and services at the level necessary to capture a significant market base and, consequently, to expand employment opportunities and increase profits. The businesses have dealt with this issue by attempting to provide specialized services that can attract a portion of the market base. The "partners" work together to create a market niche for the product within the broader community by continually asking. "What features of the business can capitalize on our resources and attract customers?" So, for example, the car wash has attempted to target populations that would be particularly interested in their "hands on," non-mechanical techniques. While these strategies have managed to keep the businesses "in the black," they have not always been able to achieve the profit levels desired to ensure a continual increase in consumer income and, in some cases, to cover the operating costs associated with ongoing maintenance.

As I look back to the past I can see how far we have come-from hockey masks to hydrangeas! I can recall the days of the workshop counting hockey masks endlessly where every day was very much like the day before. Today I enjoy the different challenges our business faces. It is so rewarding to overcome hurdles and to see what our green thumbs can produce. The Associates have such a keen sense of ownership and loyalty to the Greenhouse, which is a source of inspiration to me. They have made such a commitment to the business through good times and bad. For the future I hope to see each Associate's monetary reward increase as the business grows.

\section{(Mary Anne Buller, Vocational Rehabilitation Services)}

While VOCEC has been fortunate to receive rent-free space, there are indications that the present Ontario government is decreasing its occupancy of leased premises. Should some of the businesses be faced with the need to relocate, it could alter drastically the operation of the corporation. The Board of VocEC has been attempting to deal with this concern proactively by addressing the significant questions: "Where could we locate? What are the desired characteristics of a business location? How might businesses be organized to ensure economic viability while paying market-value rents?" No longer a novice in business development, the Board is now in a position of having considerable experience upon which to draw. For example, establishing the library-based cafés has demonstrated the potential of a partnership model, elements of which might be used to facilitate the portability of other businesses.

An important responsibility for the corporation is ongoing monitoring of the extent to which the relationships between consumers, service providers, and the VOCEC Board actually represent true partnerships. With the rapid growth of the 
corporation, there is the concern that individual Associates will have less opportunity to access the Board directly and to influence decisions at the level of the corporation. There is also the concern that the Board will have less opportunity to monitor the health of the individual businesses with respect to the level of consumer direction and the strength of the consumer community. Strategies to address these concerns have included surveying Associates regarding their perceptions of their involvement in the businesses, assigning a Board member to each business, and including reports directly from the businesses on the agenda of Board meetings.

Developing businesses that are not sheltered but are, in fact, directly dealing with the public, has been a great challenge to the staff. We are leaming together with the consumers in areas of business in which we had no former experience or training. We must be sensitive to consumers' needs, yet still put demands on them to meet the high expectations of the job to ensure the continued success of the business. Some individuals thrive as they discover that they are able to develop skills, confidence, and independence in a community job. Associates, staff, and Board members alike, have all grown and benefited by this whole process. We have all taken the approach that the risk of failure has been worth it. The businesses that VOCEC has under its umbrella may not suit the needs of everyone, but we have so many consumers who find that it suits them and that makes it worthwhile.

(Karen McCourty, Vocational Rehabilitation Services)

\section{CONCLUSION}

The unemployment rates for people with psychiatric disabilities, particularly those with prolonged psychiatric disorders, are staggering. This lack of meaningful, paid employment negatively impacts on the course of psychiatric disorder, general health, quality of life, and community participation. In addition, high unemployment rates reflect the social marginalization of a group of people who have considerable strengths. The transformation of traditional sheltered workshops to affirmative businesses has emerged as an innovative approach to creating real work opportunities in partnership with people with psychiatric disabilities.

This paper has described the experiences of the vocational services of one provincial psychiatric hospital in developing affirmative businesses from existing sheltered workshop resources. Although the outcomes appear to have been largely favourable, there is a need for ongoing evaluation to understand more fully the impact of these endeavours. The paper has highlighted the conditions that served as a catalyst for the transformation and the multiple, ongoing strategies used to ensure a successful shift to a power-sharing model of business development.

\section{RÉSUMÉ}

Le Club d'Emploi Voix, Occasions et Choix (CEVOC) est un organisme à but non lucratif qui regroupe plusieurs autres et qui vise à favoriser la création d'entreprises non discriminatoires afin de créer des emplois pour les bénéficiaires des services en santé mentale. Jusqu'à maintenant, 5 entreprises indépendantes ont êté créées en transformant les ressources d’ateliers-protégés dans 
I'hôpital psychiatrique de Kingston tandis que 2 autres ont été fondées en collaboration avec la bibliotheque municipale.

Cet article fournit une description du CEVOC et comprend une vue d'ensemble de l'approche commerciale non discriminatoire ainsi qu'une description de la structure de l'organisation et du processus de développement d'entreprisc. Diverses réflexions personnelles donnent un aperçu des expériences vécues par les bénéficiaires, le personnel et les membres du conseil d’administration de l'organisme.

\section{REFERENCES}

Allen, J.B., \& Granger, B. (1996). Consumer-run entrepreneurial businesses: Issues and opportunities. In C. Mowbray, C. Moxley, C. Jasper, \& L. Howell (Eds.), Consumers as providers in psychiarric rehabilitation. Maryland: International Association of Psychosocial Rehabilitation Services.

Bennett, E.M. (1992), Community economic development: A strategy for primary prevention. Canadian Joumal of Community Mental Health, 11(2), 11-33.

Friesen, M., \& Viti, F. (1994). Group hallucinations: Overcoming disbelief. Toronto: Consumer Survivor Business Council of Ontario and the National Network for Mental Health.

Hart, K. (1992). Away express: A way to empowerment through employment. Canadian Journal of Commanity Mental Health, $/ I(2), 73-77$.

Krupa, T. (1998). The consumer-run business: People with psychiatric disabilities as Entrepreneurs. Work: A Journal of Prevention, Assessment \& Rehabilitation, 11, 3-10.

Phillips Group (1990), Ministry of Health operational review of psychiatric hospitals vocational programs final report. Toronto: Mental Health Facilities Branch, Ministry of Health.

Radloff-Gabricl, D. (1997). A partnership to transform a sheltered workshop to a consumer run business: Reconstructing the work environment towards consumer empowerment. Untpublished master's thesis, Queen's University, Kingston, Ontario.

Trainor, J., and Tremblay, J. (1992), Consumer/survivor businesses in Ontario: Challenging the rehabilitation model. Canadian Joumal of Community Mensal Health, 11 (2), 65-71.

Voices, Opportunities \& Choices Employment Club. (1994). Director's Manual. Kingston, Ontario: Kingston Psychiatric Hospital.

Warner, R., \& Polack, P. (1993). An economic development approach to the mentally ill in the community. Washington: National Institute of Mental Health. 